\title{
Vices in Autonomous Paternalism: The Case of Advance Directives and Persons Living With Dementia
}

\author{
Sungwoo Um \\ [Penultimate version] Please do not cite without permission
}

\begin{abstract}
Advance directives are intended to extend patient autonomy by enabling patients to prospectively direct the care of their future incapacitated selves. There has been much discussion about issues such as whether the future incompetent self is identical to the agent who issues the advance directives or whether advance directives can legitimately secure patient autonomy. However, there is another important question to ask: to what extent and in what conditions is it ethically appropriate for one to limit the liberty or agency of one's future incompetent self by issuing an advance directive?

In this paper, I use a virtue-ethical approach to explore this question, focusing on the case of an advance directive for the future self with moderate dementia. First, I examine virtuous attitudes with regard to autonomy and argue that one can manifest vices or ethically undesirable character traits in trying to intervene in the future self's life. In particular, I argue that this case can manifest vices such as disdainfulness, intellectual arrogance, and self-dictatorship, which is the vice of trying to control one's life to an excessive degree, and that a self-dictator fails to give due moral consideration to the future self's liberty or agency. I then introduce the Daoist idea of wu-wei, which recommends embracement of what happens in one's life, as one of the possible remedies for the overemphasis on the value of autonomy and control.
\end{abstract}

\section{Introduction}

Autonomy is widely regarded as a crucial value to respect in medical practice. Advance directives, the documents permitting legally competent patients to make medical decisions concerning their future incompetent selves, are one example of a legal apparatus devised to respect patient autonomy. That is, they are intended to extend patient autonomy by enabling patients to prospectively direct the medical treatment of their future incompetent selves. There has been 
much discussion about issues such as whether the future incompetent self is identical to the agent who issues the advance directives ${ }^{1}$ or whether advance directives can legitimately secure patient autonomy. ${ }^{2}$ However, there is another important question to ask: to what extent and in what conditions is it ethically appropriate for one to limit the liberty or agency of one's future incompetent self by issuing an advance directive? ${ }^{3}$

In this paper, I use a virtue-ethical approach to explore this question, focusing on the case of an advance directive for the future self with moderate dementia. First, I examine virtuous attitudes with regard to autonomy and argue that one can manifest vices or ethically undesirable character traits in trying to intervene in the future self's life. In particular, I argue that this case can manifest vices such as disdainfulness, intellectual arrogance, and self-dictatorship, which is the vice of trying to control one's life to an excessive degree, and that a self-dictator fails to give due moral consideration to the future self's liberty or agency. I then introduce the Daoist idea of wu-wei, which recommends embracement of what happens in one's life, as one of the possible remedies for the overemphasis on the value of autonomy and control.

\footnotetext{
1 See, for example, Buchanan, A. (1988). Advance directives and the personal identity problem. Philosophy E Public Affairs, 277-302; Buchanan, A. E., \& Brock, D. W. (1989). Deciding for others: the ethics of surrogate decision making: Cambridge University Press; DeGrazia, D. (1999). Advance directives, dementia, and 'the someone else problem'. Bioethics, 13(5), 373-391; Dresser, R. (1986). Life, death, and incompetent patients: Conceptual infirmities and hidden values in the law. Ariz. L. Rev., 28, 373; Furberg, E. (2011). Advance Directives and Personal Identity: What Is the Problem? The Journal of Medicine and Philosophy: A Forum for Bioethics and Philosophy of Medicine, 37(1), 60-73. doi:10.1093/jmp/jhr055.

2 See, for example, Buford, C. (2008). Advancing an advance directive debate. Bioethics, 22(8), 423-430; Davis, J. (2007). Precedent autonomy, advance directives, and end-of-life care; Shaw, D. (2012). A direct advance on advance directives. Bioethics, 26(5), 267-274; Varelius, J. (2018). Advance Directives and the Descendant Argument. Paper presented at the HEC Forum; Vogelstein, E. (2016). Autonomy and the moral authority of advance directives. Journal of Medicine and Philosophy, 41(5), 500-520.

${ }^{3}$ In this paper, I use 'liberty' and 'agency' interchangeably to refer to the minimal ability to make choice based on one's own values and preferences.
} 
Forthcoming in Bioethics

The discussion will be focused on a specific case of a patient issuing an advance directive concerning her future self with moderate dementia4:

Amita writes an advance directive stipulating that if she should ever develop even moderate Alzheimer's, her death should be hastened - either by action or omission - as soon as possible. Amita understands that Alzheimer's progresses slowly, so that honoring her request might substantially shorten her life, and that she may still have quite a happy and contented life at the later stage of moderate dementia. Later, when Amita develops Alzheimer's, she turns out to be happy and content most of the time. She is now in the middle phase of Alzheimer's and she is no longer competent to make her own medical decisions, but still has many things she enjoys and values. Overall, she appears to be enjoying her life and she occasionally expresses to her caregivers a desire to live and a fear of dying.

I will call Amita at the moment of writing an advance directive ES (the earlier self) and Amita in the middle phase of Alzheimer's LS (the later self). ${ }^{5}$ I assume that LS is judged to be incompetent

\footnotetext{
${ }^{4}$ I adapted Jennifer Hawkins's example (Hawkins, J. (2014). Well-being, time, and dementia. Ethics, 124(3), 507-542), which is in turn inspired by the case of Margo (Firlik, A. D. (1991). Margo's logo. JAMA, 265(2), 201-201.).

${ }^{5}$ I follow Hawkins's stipulation that Amita-as-LS has similar capacities as the individuals discussed in Dworkin, R. (2011). Life's dominion: an argument about abortion, euthanasia, and individual freedom: Vintage; Dresser, op. cit. note 1; Jaworska, A. (1999). Respecting the margins of agency: Alzheimer's patients and the capacity to value. Philosophy \& Public Affairs, 28(2), 105-138; and McMahan, J. (2002). The ethics of killing: Problems at the margins of life: Oxford University Press, USA. LS "has lost a lot of memory and no longer has a sense of herself as someone with 'a whole life, a past joined to a future, that could be object of any evaluation or concern as a whole' (Dworkin, op. cit. note 5, p. 230). She does, however, still care deeply
} 
regarding medical decisions and thus lacks the right to rescind the advance directive. ${ }^{6} \mathrm{I}$ also assume that ES's intention is not limited to avoiding the final vegetative stages of the illness and unbearable suffering that some patients experience throughout. Rather, ES issues the advance directive to remain as the author of her life as a whole who has full control of her life, even at the cost of LS's life, which LS enjoys and values. In addition, to avoid debates concerning the issue of personali identity, I assume that ES and LS are the same individuals even if they have very different values and preferences.

My analysis in this paper focuses on a vice that ES may manifest in issuing the advance directive regarding LS to protect the integrity of Amita's life as a whole. It is important to note that my aim is not to argue against advance directives as a policy or the practice of issuing them in general but to show what kind of vices can be revealed when someone like ES issues an advance directive in the way she does. What I am pointing to is the possibility that one may reveal ethically problematic attitudes in issuing an advance directive in some cases by introducing vices that may be manifested in such contexts. I do not claim that the practice of issuing advance directives is generally ethically problematic even from a virtue-ethical perspective. Thus, the discussion in this paper is limited to Amita's and other sufficiently similar cases and does not focus on the practice of advance directives in general.

about certain things in a more than merely experiential way; i.e., she retains the capacity to value, even if she no longer generates new values (Jaworska, op. cit. note 5, pp. 112-116)" (Hawkins, op. cit. note 4, p. 508). ${ }^{6}$ The right I have in my mind in this paper is a moral right, although it may offer a strong ground for establishing a legal right that protects it. The concept of the (moral) right to autonomy is used to be contrasted to the concept of virtue, and my point here is to show that the latter captures something of ethical importance while the former doesn't. For this purpose, I believe, the distinction between moral or legal rights would not affect the main point I make in this paper. 
There have been arguments supporting the claim that a patient like Amita should be allowed to die following ES's will expressed in her advance directive. Dworkin, for example, makes such an argument appealing to the idea that "people have a right not to suffer indignity". He distinguishes a person's critical interests, those that makes her life as a whole genuinely better to satisfy, from that person's experiential interests, those in having enjoyable felt experiences such as listening to music but not essential to her understanding of what constitutes a good life. According to him, in respecting someone's autonomy, it is more important to satisfy the former kind of interests. Given this distinction, someone like ES has critical interests while someone like LS lacks them and only have experiential interests. ${ }^{8}$ Thus, Dworkin would argue that, ES's critical interests expressed in her advance directive should be followed, even if it means disregarding LS's experiential interests, because it is the way to respect ES's autonomy and to preserve the ‘dignity' of Amita's life as a whole. ${ }^{9}$

Other philosophers argue that it may be wrong to let LS die just in order to respect ES's autonomy, albeit for varying reasons. Three representative positions in this lines are suggested by Rebecca Dresser, Agnieszka Jaworska, and Jennifer Hawkins. Dresser argues the earlier patient is not the same person as the later one and thus that the advance directive should not have authority over the latter. ${ }^{10}$ In contrast, Jaworska's argument appeals to the claim that the later demented patient's "capacity to value by itself does, in a very important sense, render a person capable of autonomy". ${ }^{11}$ According to Hawkins's yet another view, letting a patient like Amita

\footnotetext{
${ }^{7}$ Dworkin, op. cit. note 5, p. 233.

${ }^{8}$ Dworkin, op. cit. pp. 179-217.

${ }_{9}^{9}$ Dworkin, op. cit. note 5; see also McMahan, op. cit. note 5.

10 Dresser, op. cit. note 1.

11 Jaworska, op. cit. note 5, p. 130.
} 
die is not good for her because past desires she no longer has are not determinative of her current good. ${ }^{12}$

While I am sympathetic to the latter group of philosophers, my approach is different from theirs in important respects. First, my view does not assume or rely on the claim that ES and LS are different persons. Second, I assume that ES has a right to decide LS's medical treatment and that LS does not have a right to revoke it. Finally, my main focus is not on the overall well-being of Amita but on ES's virtuousness and viciousness. I aim to establish a philosophical ground that can help patients in a situation similar to ES's to make a more virtuous decision concerning their future self by identifying potential vices manifested in ES's act of issuing the advance directive. My discussion centers on how a virtuous person would tend to exercise her right to make decisions regarding LS's medical care and in what sense ES exemplifies vices.

\section{A Virtue-Ethical Approach to Advance Directives}

This paper highlights virtues and vices as important considerations in determining ethical appropriateness of effectuating advance directives. I believe my virtue-ethical approach to the issue of autonomy related to advance directives can draw attention to some important ethical aspects that have not been addressed in consequentialist or deontological approaches. First, it does not focus on calculating potential outcomes of effectuating advance directives, because I believe the good consequences do not exhaust the relevant ethical considerations and also

12 Hawkins, op. cit. note 4. 
because it is extremely difficult to accurately predict the consequences in the distant future. Second, the virtue-ethical approach can help us examine the ethical appropriateness of issuing an advance directive concerning one's future self, which is not fully captured in terms of a right to autonomy or duty to respect such a right.

As Rosalind Hursthouse illustrates with the case of abortion, the ethical considerations of a certain medical practice are not fully captured in terms of the agent's rights. ${ }^{13}$ Even assuming that the right for bodily integrity allows a woman to have an abortion, in exercising it, she "can do something cruel, or callous, or selfish, light-minded, self-righteous, stupid, inconsiderate, disloyal, dishonest - that is, act viciously". ${ }^{14}$ My approach to advance directives in this paper is inspired by Hursthouse's. Even assuming that a patient's right to autonomy allows her to effectuate an advance directive against her future incompetent self, I argue, she may exercise it in a disdainful, intellectually arrogant, or self-dictatorial way.

\section{The Virtue of Autonomy}

Before discussing the kind of vices that can be manifested in exercising one's autonomy by issuing an advance directive, let us first examine the value of autonomy and how a virtuous person would use it. By autonomy, I mean the broad sense of self-determination or self-government rather than a 'thicker' Kantian sense that involves making decisions in conformity to and motivated by the moral law. To be autonomous is to govern and determine how one's life goes,

${ }^{13}$ Hursthouse, R. (1991). Virtue theory and abortion. Philosophy \& Public Affairs, 223-246.

${ }^{14}$ Ibid: 235. 
which is a matter of being an 'author' of the narrative of one's life. Although autonomy is widely regarded as a value that merits respect and protection, there can be better or worse ways to exercise it. The virtue of autonomy refers to the disposition to exercise and treat autonomy in an ethically appropriate manner.

The virtue of autonomy can be understood as a mean state of character between two extremes. ${ }^{15}$ As Joel Feinberg states, various features of autonomy-e.g., self-reliance, independence, and self-control-can be virtues "only when their elements exist in just the right degree, neither too little nor too much" ${ }^{16}$ While self-reliance, independence, and self-control can indeed be virtues, they are not the sorts of virtues such that the more one has the better without qualification. A person who has the virtue of autonomy is one who is neither deficient nor excessive in exercising one's autonomy.

At one extreme, a person who is deficient in autonomy would be too passive and too dependent on others. We may call this person a heteronomous person since she tends to allow someone or something other than herself to govern her own life to an excessive degree. In other words, such a person is not sufficiently committed to governing her own life as its master. She would, for example, tend to defer her own important life decisions to someone else, such as family members and close friends, the masses, or dictators. A heteronomous person can take various forms: "credulous, gullible, compliant, passive, submissive, over-dependent, servile" ${ }^{17}$

\footnotetext{
${ }^{15}$ For the idea of the virtue of autonomy as a mean, see Benson, J. (1983). Who is the autonomous man? Philosophy, 58(223), 5-17; Feinberg, J. (1986). The Moral Limits of the Criminal Law. Volume 3, Harm to Self: New York.

${ }^{16}$ Feinberg, op. cit. note 13, p. 46.

17 Benson, op. cit. note 13, p. 5.
} 
At the other extreme, there is the vice of exercising autonomy in an excessive way, which I will call hyper-autonomy. There can be various ways to be hyper-autonomous. For example, one may give undue priority to autonomy over other important values such as well-being and justice or refuse to seek others' help when that is beneficial and wise. Since it is a matter of exercising one's autonomy to an excessive degree, one can be hyper-autonomous even when no one else is interfering with one's life decisions. Such a person tends to be in some sense obsessed with controlling one's own life. One form of hyper-autonomy is "solipsism...or arrogant selfsufficiency," which John Benson characterizes as a disposition "to rely on oneself when it would be more judicious to accept the counsel or testimony of others" ${ }^{18}$

However, there is another important form of vice that involves excessive autonomy that is related to oneself rather than to others or non-self. This is what I call self-dictatorship. Selfdictatorship is the vice of exercising autonomy to control one's self in different stages of one's life to an excessive degree. What is distinctive about self-dictatorship is that it is related to a part or phase of one's own life, rather than other people's. While the disposition to have control over other people has been widely regarded as a vice, the vice of trying to have excessive control over some aspect of one's own life has rarely been discussed, if ever. A dictator oppresses other people's liberty and by controlling their lives according to her own will, disregarding their values and preferences. Even a benign dictator who is not very harsh on her subjects can still be a dictator. We can understand Amita's case in a similar way since, from LS's perspective, ES is a dictator

${ }^{18}$ Ibid: 5-6. 
who tries to oppress her liberty. If so, self-dictatorship would be a vice in relation to one's future self in a similar way in which dictatorship is a vice in relation to other people.

Joel Feinberg expresses similar worry on the vice related to excessive autonomy:

When the self in control is a ruthless autocrat (King Reason) imposing order with an iron hand, then inner conflict is squelched only at great cost to elements of the self, and the presentation of rigid narrowness to the outside world. Self-control can be totalitarian repression, and self-discipline can become self-tyranny. The inner peace so secured is won only by driving dissident elements underground to plot subversion. ${ }^{19}$

While Feinberg seems to focus on the elements of self in a synchronic sense (e.g., about conflicting desires and values), my paper introduces the diachronic sense of such elements (e.g., the earlier self and the future self). With this difference in mind, we can see how his point can be applied to Amita's case. Just like the "ruthless autocrat" here, ES is trying to achieve her "inner peace" by silencing the dissident elements of self, which in our case is her future self, LS.

One may think that I value the autonomy of the later self (LS) above the earlier self (ES). If this is true, it may seem unfair to ES, especially given that LS's life is not separate and distinct from ES's life. LS is likely to be cared for and surrounded by people from ES's life. LS has the ability to destroy the legacy, relationships, and financial means of ES. Given such facts, it may be argued, it would not be fair to ES to favor LS. ${ }^{20}$

\footnotetext{
${ }^{19}$ Feinberg, op. cit. note 13, p. 46.

${ }^{20}$ I thank the anonymous referee for raising this issue.
} 
In response, let me first mention that I do not value LS's autonomy above ES's. The reason I focus on ES's potential vice of hyper-autonomy rather than LS's is just because, given the temporal asymmetry in control between ES and LS, ES would have more control over LS in most cases. For example, most of a person's decisions and actions will shape and limit the option-range for her future self. Thus, the way I discuss the relationship between ES and LS does not manifest unfair partiliaty toward ES.

Of course, despite this unavoidable asymmetry the earlier and the later selves, there are ways in which the later self can be self-dictatorial against the earlier self. For example, someone's later self may thwart her earlier self's project, ruin her relationships, or repudiate her commitments. If the later self does so just to make her life consistent with the later self's conception of good life, then it can be said that she is, like Amita's ES, manifesting self-dictatorshp. However, it would be especially hard, if not impossible, for someone like LS to manifest such a 'backward' self-dictatorship, since she is described as an incompetent patient who cannot actively thwart ES's projects or ruin her relationships.

\section{Vices in Autonomous Paternalism}

Concerning the idea of self-dictatorship, it might be wondered how one can be a 'dictator' to one's own self, given that autonomy is a matter of governing oneself anyway. To address this concern, it would be helpful to begin by showing how one can be paternalistic to oneself. As Douglas Husak points out, there is no conceptual problem in the idea of paternalism towards oneself 
because "an agent can make decisions at one time that result in subsequent interferences with his liberty". ${ }^{21}$ We can call it autonomous paternalism. In Amita's example, ES is committing autonomous paternalism when she controls the medical treatment of LS according to ES's own will expressed in the advance directive. What ES does is autonomous - at least from ES's perspective-in that it is ES herself, not someone else, who is trying to exercise her agency to make something happen in the course of her life. On the other hand, it is paternalistic from LS's perspective in the sense that it interferes with the liberty or agency that LS can retain even if she lacks the full competence required for having the right to autonomy. According to Husak's framing, the agent "who treats himself paternalistically consents to an interference (perhaps to be applied by others) at a later time". ${ }^{22}$

There are some vices other than self-dictatorship that may be involved in autonomous paternalism. First, ES's attitude in creating the advance directive may manifest what I call disdainfulness, which involves the attitude of regarding a certain kind of person or life as worthless. The state of LS described in the advance directive is a state of moderate dementia in which one cannot have a picture of life as a whole but still enjoys one's experiential life. If ES asks to stop providing medical treatment necessary for maintaining her life when her condition meets that description, it may express a sort of disdain to people whose lives also fit that description. The underlying motivation might be that LS's state does not fill well into the 'dignified' form of life

${ }_{21}^{21}$ Husak, D. N. (1981). Paternalism and autonomy. Philosophy \& Public Affairs, 27-46, p. 42.

${ }^{22}$ Husak, op. cit. note 17, p. 43. One may believe that $\mathrm{X}$ acts paternalistically on $\mathrm{Y}$ only if $\mathrm{X}$ believes her action is good for $\mathrm{Y}$ herself. Given that the identity of ES and LS is not settled, it is not easy to see whether ES's issuing the advance directive satisfies this condition. However, we can say at least that ES believes it is good for Amita's life as a whole, which ES believes to includes LS as well, regardless of whether LS agrees or not. 
as a whole that ES envisions in her mind. Let me give an analogy. Suppose that Sam has just been rejected from a university he wanted to enter. Now he deprecates himself 'I'm so stupid! My life is worthless!!" This attitude reveals not just the vice of self-deprecation, but also that of disdainfulness, which involves disdain on others in a similar condition. That is, it means-even if he is not consciously doing so-he is ready to disdain those who are not smart enough to enter that university and see their life as not worth living. If ES believes that a life of that sort is not worth living, objectively speaking, then it may reveal the vice of looking down on a sort of life that might be worthy at least to those whose life it is.

ES may deny that it expresses disdain to other people's life satisfying that description, and say that that sort of life is not worth living only for ES herself. She may reply, "Oh, don't get me wrong! I just mean that my life would not be worth living if I get dementia, but others' lives are not." But then the attitude underlying making herself an exception may also reveal another form of immodesty, which is the attitude of regarding oneself someone special, so special that what is worthy for others is not worthy enough for herself. Either way, this kind of attitude may be involved ES's issuing the advance directive in relation to her future self. In ES's judgment, her future self, LS, does not deserve to be seen as someone whose life is worth living. Even if her life does not fit the narrative integrity that ES has in her mind, that does not mean ES can disdain the kind of life that LS lives, regardless of whether that is her own life or someone else's. It might be tempting to think that we are free to have whatever degrading or pejorative attitudes towards ourselves and we put such self-directed attitudes separately from similar attitudes directed to others. However, it is not necessarily true, especially in cases where there is a radical difference between the 'selves.' 
There is also a vice possibly related to ES's epistemic attitude, which we may call intellectual arrogance. The act of issuing an advance directive about one's future self is based on the assumption that one has sufficient knowledge to make a wise decision about the future self. In issuing an advance directive, the patient tends to assume that she knows what is better for the future self and that there will be no significant change in the circumstances. As Dresser correctly points out, however, "the competent patient's former choices cannot incorporate precise and upto-date information bearing on the specific treatment dilemma that eventually develops; nor are they necessarily the choices the patient would make when faced with the actual treatment conflict" ${ }^{23}$ We have more reasons for having this kind of worry in the case of dementia, which normally involves a radical change of the character or personality of the patient herself, not just the future circumstances. To make important medical decisions about the future self based on one's such imperfect and vague impression about what it would be like to be a patient with the disease described in the advance directive may reveal the vice of intellectual arrogance. It would be comparable to the case in which one makes judgments about other people and their life just based on external observation and inferences without going through the life oneself from the firstperson perspective.

Due to the uncertainty about the specific situation that the future self will face, it may be argued that efforts should focus on the individual's fundamental definitions of self and what a life worth living means to the individual rather than identifying specific treatment options that are acceptable for the future self. This idea seems inadequate to deal with the uncertain future

${ }^{23}$ Dresser, op. cit. 
because an individual's definition of self or that of a worthy life itself may change over time, just like the case of ES and LS. An adequate view should be sensitive to such a change and be careful not to unfairly prioritize the view of the self at one point over that of the self at another point. ES in my example is manifesting the vice of self-dictatorship precisely because she tries to determine the course of LS's life based on her own conception of a good life even if LS's may go against her own.

Autonomous paternalism itself does not necessarily manifest vice, however. Just like other cases of paternalism, a case of autonomous paternalism may or may not be morally objectionable depending on whether there are sufficient reasons that justify such practice. If, unlike Amita's case, the earlier self's values and preferences are not radically different from the later self's, then the former's interfering with the latter's agency for the sake of what both want and value may be justified. Consider the case of a weak-willed person, Will. He values being in good shape while loving to eat cookies. But, being weak-willed, he knows that his future self will devour chocolate cookies when he goes to his friend Sondra's party next week. Thus, he decides to make a prior commitment to refrain from eating cookies, by signing a contract with Sondra that he will give her $\$ 100$ if he eats any cookies at her party.

This case is different from Amita's in several important senses. First, Will's relevant values and preferences do not change before and after signing the contract. That is, he values being in good shape but desires to eat a lot of cookies now and will remain this way when he goes to the party a week later. In this sense, this case of autonomous paternalism can be justified because Will-at-the-party would also endorse that it is valuable for him to be on a diet. In this sense, refraining from eating cookies is good for-and believed so by - 'both' of Will's earlier and later 
selves. Self-dictatorship presupposes some important change in one's values, as in our case of Amita. It involves the earlier self's interfering with the later self's liberty by making some decision over the latter against what she wants and values. In Amita's case, ES's and LS's values are in conflict because what the former values - protecting her narrative integrity - is inconsistent LS's continuing her life.

Another possible justification for autonomous paternalism may be found from external sources. Given that liberty is not the only value to consider, an act of autonomous paternalism can be justified by appealing to other values. For example, suppose that the reason ES is issuing an advance directive over LS is that she does not want her to be a burden to her family and to society. Or in a more obvious case, ES might issue such an advance directive to prevent LS from harming people around her and the society. If so, even if it is morally important for ES to give due considerations to LS's liberty, if it involves serious harm to other values (e.g., social value or many other people's well-being), then ES's act may not be an instantiation of self-dictatorship. It can be a painful yet morally praiseworthy act of altruism. However, in Amita's case, there is no inherent moral objectionability about LS's continuing to live from anyone's perspective. That is, even if ES does not issue an advance directive LS will not do anything that is morally objectionable in itself. Recall that the reason for ES's issuing the advance directive is not because she believes that LS's life will be morally problematic but just because such a life would not be consistent with the integrity of Amita's life as a whole that ES tries to project.

Whether and how much someone's advance directive manifest vice also depends on what its content is. For example, if ES said to withhold food and water and - if LS seemed agitated by non-feeding or sought food - to sedate LS, then it can be said that ES is revealing the vice of self- 
dictatorship more intensely than when she said not to treat an infection, since the former is intended to intervene with LS's life to a larger degree by making her death much more assured.

Amita's case should also be distinguished from the case of advance directives where the later self is in a permanently unconscious state. For its point is not just to prioritize respecting the earlier self's autonomy over the later self's liberty but to give epistemic access to the unconscious later self, so that (surrogate or otherwise) decision-makers can have some clue on what the patient would have chosen if she were conscious. In contrast, the advance directive in our case is different, because the present patient is still conscious and has some ability to make choices - or at least to express her values and preferences. Thus, the choices expressed by ES in the advance directives do not serve as a good piece of evidence for LS's current preferences. This is more so if the values and preferences of the earlier self and that of the later self conflict with each other. The issue of self-dictatorship does not arise in the case of the advance directive concerning one's unconscious state because there is no element of autonomy (i.e., liberty or agency) in the unconscious later self that may conflict with the autonomy of the earlier self who issues the advance directive. Especially when there is no or little chance for the patient to recover consciousness, the consideration of the unconscious patient's liberty does not usually have to come into the picture. ${ }^{24}$

\footnotetext{
${ }^{24}$ Of course, there might be a case where the unconscious state is only temporary. One may ask how long a state of "unconsciousness" needs to last or be expected to last for an advance directive be relevant in my view. But the point of comparing a patient with moderate dementia and one who is unconscious is just to show that the former, given her agency, may still has agency to be respected that the latter clearly lacks. I do not deny the possibility that even the permanently unconscious patient may still have some "right to life" that should be respected. What I assume is that such a patient does not have the minimal agency that a patient with moderate dementia like LS has. For a debate concerning what is the best way to respect an unconscious patient's autonomy in a medical emergency, see, for example, Enoch, D. (2017). Hypothetical Consent and the Value(s) of Autonomy. Ethics, 128(1), 6-36.
} 
One may argue that my view on radical change and self-dictatorship would collapse into the view that the current person shouldn't be bound be the former person because the change between them is radical enough to make the latter person unidentical to the former. While this objection is understandable given the apparent similarity, my view is distinct from such a view because it does not rely on ES and LS's being different persons. Even if ES and LS are identical despite the radical change, according to my view, avoiding the vice of self-dictatorship would demand ES not to overuse her right to autonomy by limiting LS's liberty or agency. If ES and LS were different persons, then the vice ES would manifest is dictatorship, rather thant 'self'-dictatorship I describe here.

\section{From Rights to Virtue}

I have assumed that there is something morally objectionable in ES's issuing the advance directive to interfere with LS's liberty. If this assumption is correct, an adequate ethical theory should explain which aspect of ES is morally objectionable. My suggestion is that this aspect can be better captured in terms of virtue rather than in terms of rights. In Amita's example, ES is competent and thus has the right to autonomy while LS is incompetent and lacks such a right. So it is hard for a rights-based approach to capture what is morally objectionable about ES because what ES does is within her right to autonomy and that LS lacks the right to revoke what ES does on her. In other words, ES's issuing an advance directive that limits LS's liberty is neither going beyond what her 
right to autonomy allows nor violating any right that LS has. Thus, it is difficult for a rights-based approach to explain what is morally objectionable in such a case. ${ }^{25}$

What further complicates the issue here is the fact that LS is incompetent yet still has some element of autonomy to respect (i.e., liberty or agency). If LS were competent, then ES's issuing the advance directive would not manifest self-dictatorship since LS will be able to change the plan ES made for her. Rather, it would be just another case of what we call 'planning.' (Indeed, if LS is competent, it would not even make sense for ES to issue an advance directive about LS.) However, in Amita's case, LS is incompetent and thus does not right to autonomy that enables her to revoke what ES's advance directive says. This asymmetry makes ES's 'abuse' of her power over LS more problematic.

However, even if LS lacks full competence and thus lacks the right to autonomy, given the moderateness of her state, it is reasonable to say that she still retains some element of autonomy. It would be absurd to say that an unconscious patient is on a par with a patient with moderate dementia with regard to autonomy just because they are both categorized as incompetent. One important sense of respecting someone as a person is to give due moral weight to ensuring that the given decision is the result of her own choice or control. Thus, her liberty deserves some moral consideration at least as a part of what makes her life go well, even if it is not sufficient to ground the right to autonomy. To say the least, LS's valuing and preferring her continuing to live should be given due moral consideration. Insofar as ES fails to give due

\footnotetext{
${ }^{25}$ For more on the relationship between virtue and ethically appropriate use of rights, see, for example, Meyer, M. J. (1997). When not to claim your rights: The abuse and the virtuous use of rights. Journal of Political Philosophy, 5(2), 149-162.
} 
Forthcoming in Bioethics

consideration on LS's liberty without sufficient justifying reasons, it seems that there is something morally objectionable about what motivates her. Thus, if ES were less obsessed with being 'autonomous' or controlling her life as a whole and cared more about LS's living according to her own values and preferences, ES would not have issued such an advance directive.

\section{The Daoist Idea of $W u-W e i$}

So far, I have analyzed the moral complexity of extending an agent's autonomy through the advance directive, especially when she goes through a radical change over time. Let me finish this paper by introducing the Daoist idea of $w u$-wei, which advises us to embrace the flow and the course of Nature (zi-ran), as one of the possible remedies for the excessive focus on autonomy or self-determination in Western culture.

The idea of respect for autonomy is rooted in the emphasis on being the author (master or owner) of one's own life. Although respecting autonomy does have significant ethical importance, if the use of autonomy can be excessive, it would be helpful to explore an alternative view on how to lead one's life. I think we can find valuable insights and inspirations from the tradition of Daoism, which is a school of thought represented by Chinese philosophers such as Laozi and Zhuangzi. Unlike the Western tradition, which has heavily emphasized the importance of being an autonomous agent who governs one's own life, Daoists have been critical toward the excessive emphasis on human agency. Although they did not criticize the idea of obsession with autonomy in the modern sense, they were generally against the sharp distinction between 'agents,' who 
have control over their life and the world, and the rest of the world. Rather, Daoists tend to identify agents such as human beings as part of Nature, rather than as some special beings. What they recommend is to live in accordance with the Way $(D a o)$ or the patterns of Nature, as opposed to striving to use one's agency against it.

Daoists present the idea of wu-wei as the remedy for the overuse of human agency and recommend gentle embracement of what happens in one's life. Although wu-wei literally means 'doing nothing' or 'nonaction,' it does not tell us not to do anything to make our life better. Rather, this idea advises us not to overuse our agency and to overcome the dichotomy between self and other. Generally speaking, the idea of wu-wei recommends us to "Let it be" or "Go with the flow." Regarding our case, Daoists may advise ES not to effectuate her advance directive and let LS enjoy her own life as Nature leads her, rather than trying to force LS's life into the narrative whole that ES strives to be the author of.

A story in Zhuangzi vividly illustrates a Daoist attitude on radical changes in one's life. In this story, Master $\mathrm{Yu}$ falls seriously ill and his body gradually becomes deformed. When his friend asks him if he resents that the "Creator" (which does not refer to a personal god like Christian God) put him in such a condition, he replies as follows:

“Why no, what would I resent? If the process continues, perhaps in time he'll transform my left arm into a rooster. In that case I'll keep watch during the night. Or perhaps in time he'll transform my right arm into a crossbow pellet, and I'll shoot down an owl for roasting. Or perhaps in time he'll transform my buttocks into cartwheels.... I received life because the time had come; I will lose it because the order of things passes 
on. Be content with this time and dwell in this order, and then neither sorrow nor joy can touch you. In ancient times this was called the 'freeing of the bound.' There are those who cannot free themselves because they are bound by things. But nothing can ever win against Heaven - that's the way it's always been. What would I have to resent?"26

In this story, Master $\mathrm{Yu}$ is showing the attitude of embracing the changes in his body and the transformation of his self rather than striving to use his agency to control it against the change. He is ready to embrace, or even enjoy, living life as the transformed self.

Perhaps the idea that we can control at least our own lives as their masters is a myth. However, it does not require more than a minute of thought to realize how many aspects of our lives are out of our control: our birth, family, and diseases, just to name a few. What is more problematic than the belief that we can control every aspect of our lives is the belief that we ought to maximize such control. Advance directives are adopted to enable a (potential) patient to control her future incompetent self. But even if we can change the path of our lives, at least sometimes it is better to let what happens just happen - in our case, being in a state of moderate dementia and gently embrace it rather than hastily striving to take steps to control one's future self before she goes through the 'transformation.'

Before closing, let me once again emphasize that I introduced the idea of wu-wei only to show one possible alternative way of thinking that can alleviate the tendency to be obsessed with exhausting or maximally exercising one's autonomy. The introduction of wu-wei is not meant to

${ }^{26}$ Watson, B. (2013). The complete works of Zhuangzi: Columbia University Press, pp. 47-48. emphasis added. 
criticize ES for trying to end LS's life in particular. It is meant to criticize overexercise of autonomy. One can also manifest self-dictorship or other vices of hyper-autonomy by trying to save, rather than by trying to put to death, one's future self if the future self is desperate to die. Moreover, as noted, wu-wei, or following the patterns of 'Nature', does not necessarily mean doing nothing against the course of 'default' process even if it is the process of diseas or illness. Being abstractly stated, the idea of wu-wei is open to many different interpretations especially in relation to particular practical contexts. But according to what I believe to be a reasonable interpretation, wu-wei can allow or even recommend some theraphies that attempts to reverse the 'default' course of disease and illness.

What the spirit of wu-wei warns us against is what I call hyper-autonomy, which is a vice of exercising one's autonomy to an excessive degree. When one's exercise of autonomy goes excessive would depend on the reading of the given situation. ES in my example manifests such a vice not because of the fact that she issued an advance directive but because she did that from her desire for narrative integrity of her life as a whole even if that may clash what her future self's strong desire to live. Also, the idea of wu-wei does not say that it is never appropriate to bind one's future self. I just wanted to say that there can be cases in which one goes excessive in exercising one's right to autonomy to bind one's future self. Thus, I can say that, for example, if ES issues the advance directive to end the unbearable suffering that LS may experience, what ES does would not necessarily go against the spirit of wu-wei or manifest self-dictatorship.

The modest lesson we can take from wu-wei is that sometimes it is more appropriate to let go of the obsession with extending your autonomy to control your future self and, in some circumstances, just embrace what happens. Although too much emphasis on embracement may 
amount to the vice of heteronomy, it is also important to avoid the vice of hyper-autonomy. A person with the virtue of autonomy would make a balanced choice between the two extremes. We may find in the idea of wu-wei an alternative way of seeing our lives and relaxing our obsession with being the controller of our life. ${ }^{27}$

\section{Conclusion}

I have shown how one may manifest vices in exercising her right to autonomy by effectuating an advance directive in certain conditions. There is little doubt that respecting the patient's right to autonomy is important. However, the patient may use this right virtuously or otherwise and too much emphasis on the right to autonomy may lead us to vices. The issue here is not about the legitimacy of advance directives as a legal practice or moral permissibility or impermissibility of issuing an advance directive such as ES's. This paper has focused on what a person like ES would do if she were fully virtuous and what would render her less than fully virtuous if she enforces an advance directive such as one described above. My aim has been to show that the lens of virtues and vices can help us to see some neglected but important aspects of ethical appropriateness that are not fully captured in terms of rights, duties, or permissibility.

I hope my paper and the relevant discussions can help patients to make a wiser choice with regard to issuing advance directives and providers to give the patients more balanced advice that fits the given particular conditions. Although my paper has focused on the case of dementia,

\footnotetext{
${ }^{27}$ See Kleinman, A. (2020). The Soul of Care: The Moral Education of a Husband and a Doctor, Penguin Books,
} for a book about caregiving for dementia from the perspective of wu-wei. 
its implications can also be applied to other similar cases where the later self is incompetent yet wishes to continue to live against the earlier self's advance directive. While it is important to keep one's autonomy away from undue influences from the outside, it is at least as important not to use it in an excessive way. Whether one has the right to autonomy is not the end of the moral story here. Even if one has such a right, one should carefully think about how to exercise it. Maximally extending your autonomy by determining your future life may not always be ethically appropriate. Your future self may lead to a life that is valuable and enjoyable in a way that you cannot imagine now. Sometimes, the best way to exercise your right to autonomy is not to exercise it. 